\title{
Face Tracking Performance in Head Gesture Recognition System
}

\author{
Rushikesh Bankar, Suresh Salankar
}

\begin{abstract}
This paper describes the comparative analysis of different face tracking methods in the head gesture recognition system. The major constraints of head gesture recognition system, i.e. face detection, feature extraction, tracking, and recognition are explained. We used adaboost algorithm for detection, and Camshift algorithm for tracking with different feature extraction methods. We performed extensive experimentations and presented a comparative analysis of tracking performance of head gesture recognition system under cluttered backgrounds, shadow and sunshine conditions. Experimental results show the robustness in face detection, tracking and direction recognition of the proposed method.
\end{abstract}

Keywords: Camshift, Camshift with BLBP, Face Detection, Face Tracking.

\section{INTRODUCTION}

A gesture is a form of non-verbal communication or non-vocal communication in which visible bodily actions like head, hand, arms or other parts of body which communicate particular messages. In human computer interaction, gesture recognition is a key research topic. The vision based gesture recognition includes applications such as sign recognition, medical assistance, electric wheelchair control, driver's vigilance and so on. The various applications based on human gestures can be categorized with respect to the different parts of the human body, such as arm gesture, body gesture, facial gesture, hand gesture and head gesture.

The primary goal of a head gesture recognition is to identify specific head gestures through a video feed. Unfortunately, like other image processing problems, face detection and tracking under cluttered backgrounds, shadows and sunshine illumination variance conditions are the critical problem in some of applications such as head gesture recognition based wheelchair control, driver monitoring, vehicular control, human-robot interaction interface etc. Higher recognition accuracy and recognition with minimal time delay are the primary criterion for head gesture

Revised Manuscript Received on June 15, 2020.

* Correspondence Author

Rushikesh Bankar*, Department of Electronics Engineering, G H Raisoni College of Engineering, Nagpur, India. E-mail: rushi.shivbaba@gmail.com Engineering, G H Raisoni College of Engineering, Nagpur, India. E-mail: suresh.salankar@raisoni.net

(C) The Authors. Published by Blue Eyes Intelligence Engineering and Sciences Publication (BEIESP). This is an open access article under the CC BY-NC-ND license (http://creativecommons.org/licenses/by-nc-nd/4.0/)
Dr. Suresh Salankar, Department of Electronics \& Telecommunication

recognition.

According to author, Z. Yan, W. Liang, and H. Lv, "An Improved Camshift based Target Tracking Algorithm", Journal of Software Engineering and Applications, 2014, 7, 1065 - 1073, author explained tracking procedure constructed on improved camshift deals with the problems such as not tracking face under different environmental difficulties [1]. Pen Lu, X. Huang, X. Zhu, and Y. Wang [2] presents Bayesian Network based system. The addition of color information into Bayesian Network, the system enhances the robustness.

According to author, Yu Shi, Ronnie Taib and Serge Lichman, "A Smart Camera for Gesture Recognition and Gesture Controlled Web Navigation", the author has explained a smart camera based on FPGA which can recognize simple pre-defined head and hand gestures [3].

Kawarazaki et al. [4] proposed a depth sensor based gesture recognition system. A sensor is used to recognize the hand gestures quickly. The system offers a hands freedom sense to the user, simplifying their daily activities by using the hands movements as the direction control input.

Klaus McDonald Maier et al. [5] presented a system of head movements of the user in an indoor environment. In this system, there are the two procedure methods which are built on the movements. Mode 1 includes generation of controlling commands for the head movements to give the controlling actions to the wheelchair. The Mode 2 employs four user's movements of head like turning to left direction, turning to right direction, upside movements as well as downside movements of the intelligent wheelchair.

\section{FACE TRACKING METHODS}

In this paper, for tracking of user's face, different methods are used with the basic camshift algorithm. The camshift is widely used real time algorithm to track the face of the user in a video. So, once the face is located in the video, the next step is to identify a feature which will track user's face. Then, we have to extract features in the input image. Camshift Algorithm is a Histogram based Tracker. It uses the histogram of pixel values to identify the tracked object.

The camshift tracking method is a fast and based on image hue. In input image, camshift finds the mean window center with unchanging window size. The camshift tracking accurately fails under the conditions such as cluttered background, sunshine, and shadow conditions. To overcome these limitations of the basic camshift, following different methods of face tracking are used.

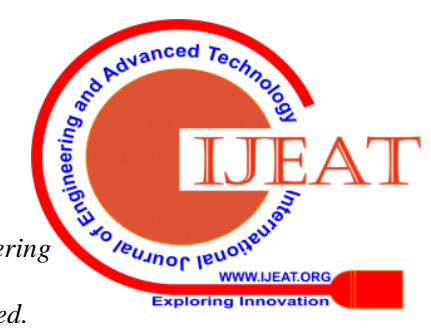


- Camshift with SIFT algorithm

- Camshift with KLT algorithm

- Camshift with UKF algorithm and

- Camshift with BLBP algorithm

\section{BASIC CAMSHIFT FACE TRACKING METHOD}

The basic camshift is widely used real time algorithm to track user's face. So, once face is located in video, the next step is to identify a feature which will track the face of the user. To track user's face, we have to extract the features in the input image. Camshift Algorithm is a Histogram based Tracker. It uses the histogram of pixel values to identify the tracked object. The camshift uses a robust non-parametric technique for the claiming density gradients to find the mode or the peak of probability distribution.

Table I shows processing time of basic camshift tracking method in head gesture recognition. The different environmental conditions considered are: cluttered background; shadow and sunshine. The head tilting directions considered are: front view; left turn; right turn; upward direction and downward direction. The parameters considered for the performance evaluation are: minimum face size and time cost per frame.

\section{TABLE I PROCESSING TIME OF FACE} TRACKING

USING BASIC CAMSHIFT ALGORITHM

\begin{tabular}{|c|c|c|}
\hline Method & Min Face Size & Time cost / Frame \\
\hline \multirow{2}{*}{$\begin{array}{c}\text { Basic Camshift } \\
\text { Algorithm }\end{array}$} & $100 * 100$ & $0.0406 \mathrm{~s}$ \\
\cline { 2 - 3 } & $123 * 123$ & $0.0333 \mathrm{~s}$ \\
\hline
\end{tabular}

Table II shows the Confusion matrix obtained using Camshift algorithm. In confusion matrix, $\mathrm{N}$ represents the total number of input sample images.

TABLE II CONFUSION MATRIX BASED ON CAMSHIFT ALGORITHM

\begin{tabular}{|c|c|c|c|}
\hline $\mathrm{N}=30$ & Predicted: No & Predicted: Yes & \\
\hline Actual: No & $\mathrm{TN}=0$ & $\mathrm{FP}=19$ & 19 \\
\hline \multirow[t]{2}{*}{ Actual: Yes } & $\mathrm{FN}=0$ & $\mathrm{TP}=11$ & 11 \\
\hline & 0 & 30 & \\
\hline
\end{tabular}

In our data base, the total sample images are 30. The 11 images are correctly tracked wherein the 19 images are not properly tracked. So, the out of these 30 images, 11 images are actual faces tracked and 19 images are faces not tracked that gives the performance accuracy to be $36.67 \%$.

\section{CAMSHIFT WITH SIFT FACE TRACKING METHOD}

Traditional camshift algorithm has some limitations. These limitations are; (i) camshift tracking fails under different illuminations, (ii) under cluttered background, camshift tracking fails and (iii) camshift tracking fails under the shadow as well as sunshine environments. To overcome these limitation, we have to use a method which extracts the features under the different conditions and with camshift tracking, it tracks face under different environments. The Scale Invariant Feature Transform (SIFT) is used to extract distinctive invariant features from images [6]. The matching between various views of an object is carried out using SIFT.

Following Table III and Table IV shows comparison of processing time and accuracy of Camshift and Camshift-SIFT algorithm for the face tracking in the head gesture recognition respectively.

\section{TABLE III COMPARISON OF PROCESSING TIME OF FACE TRACKING USING CAMSHIFT AND CAMSHIFT - SIFT ALGORITHM}

\begin{tabular}{|c|c|c|}
\hline Method & Min Face Size & Time Cost / Frame \\
\hline \multirow{2}{*}{$\begin{array}{c}\text { Basic Camshift } \\
\text { Algorithm }\end{array}$} & $100 * 100$ & $0.0406 \mathrm{~s}$ \\
\cline { 2 - 3 } & $123 * 123$ & $0.0333 \mathrm{~s}$ \\
\hline \multirow{2}{*}{$\begin{array}{c}\text { Camshift - SIFT } \\
\text { Algorithm }\end{array}$} & $100 * 100$ & $0.0047 \mathrm{~s}$ \\
\cline { 2 - 3 } & $123 * 123$ & $0.0043 \mathrm{~s}$ \\
\hline
\end{tabular}

TABLE IV COMPARISON OF PERFORMANCE ACCURACY OF FACE TRACKING USING CAMSHIFT AND CAMSHIFT - SIFT ALGORITHM

\begin{tabular}{|c|c|c|c|}
\hline Method & $\begin{array}{c}\text { Actual Faces } \\
\text { Tracked }\end{array}$ & $\begin{array}{c}\text { Faces Not } \\
\text { Tracked }\end{array}$ & Accuracy \\
\hline $\begin{array}{c}\text { Basic Camshift } \\
\text { Algorithm }\end{array}$ & 11 & 19 & $36.67 \%$ \\
\hline $\begin{array}{c}\text { Camshift - SIFT } \\
\text { Algorithm }\end{array}$ & 14 & 16 & $47.00 \%$ \\
\hline
\end{tabular}

It is observed that, using basic camshift and Camshift-SIFT, the performance accuracy is found to be $36.67 \%$ and $47.00 \%$ respectively.

\section{CAMSHIFT WITH KLT FACE TRACKING METHOD}

Kanade Lucas Tomasi (KLT) algorithm is used for tracking the human faces from a captured video frame [7]. In process of KLT Algorithm, first we capture the image or video of user. Then using Adaboost Algorithm, the face of the user is detected. After detecting the face of the user, we identify the facial features of the user. Then, using Camshift with KLT Algorithm, we track the face of the user under the different environmental conditions. Finally, the experimental results shows the face tracking of the user under the different environmental conditions.

$\mathrm{X}$
Published By:

Blue Eyes Intelligence Engineering \& Sciences Publication (C) Cobvriaht: All riahts reserved. 


\section{TABLE V PROCESSING TIME OF FACE TRACKING \\ USING CAMSHIFT - KLT ALGORITHM}

\begin{tabular}{|c|c|c|}
\hline Method & Min Face Size & Time Cost / Frame \\
\hline \multirow{2}{*}{$\begin{array}{c}\text { Camshift }- \text { KLT } \\
\text { Algorithm }\end{array}$} & $100 * 100$ & $0.0043 \mathrm{~s}$ \\
\cline { 2 - 3 } & $123 * 123$ & $0.0030 \mathrm{~s}$ \\
\hline
\end{tabular}

Table VI shows the performance accuracy of face tracking using Camshift - KLT in the head gesture recognition.

\section{TABLE VI PERFORMANCE ACCURACY OF FACE TRACKING USING CAMSHIFT - KLT ALGORITHM}

\begin{tabular}{|c|c|c|c|}
\hline Method & $\begin{array}{c}\text { Actual Faces } \\
\text { Tracked }\end{array}$ & $\begin{array}{c}\text { Faces Not } \\
\text { Tracked }\end{array}$ & Accuracy \\
\hline $\begin{array}{c}\text { Camshift - KLT } \\
\text { Algorithm }\end{array}$ & 17 & 13 & $57.00 \%$ \\
\hline
\end{tabular}

The performance accuracy using Camshift with KLT is found to be $57.00 \%$.

\section{CAMSHIFT WITH UKF FACE TRACKING METHOD}

The Unscented Kalman Filter (UKF) is used, with Basic Camshift algorithm, in the head gesture recognition, to track user's face under different environments [8].

Table VII shows the processing time of Camshift with UKF algorithm for the face tracking in the head gesture recognition.

TABLE VII PROCESSING TIME OF FACE

TRACKING USING CAMSHIFT WITH UKF

\begin{tabular}{|c|c|c|}
\hline Method & Min Face Size & Time Cost / Frame \\
\hline \multirow{2}{*}{$\begin{array}{c}\text { Camshift - UKF } \\
\text { Algorithm }\end{array}$} & $100 * 100$ & $0.0041 \mathrm{~s}$ \\
\cline { 2 - 3 } & $123 * 123$ & $0.0026 \mathrm{~s}$ \\
\hline
\end{tabular}

Table VIII shows the performance accuracy of Face tracking using Camshift with UKF in the head gesture recognition.

\section{TABLE VIII PERFORMANCE ACCURACY OF FACE}

TRACKING USING CAMSHIFT WITH UKF

\begin{tabular}{|c|c|c|c|}
\hline Method & $\begin{array}{c}\text { Actual Faces } \\
\text { Tracked }\end{array}$ & $\begin{array}{c}\text { Faces Not } \\
\text { Tracked }\end{array}$ & Accuracy \\
\hline $\begin{array}{c}\text { Camshift - UKF } \\
\text { Algorithm }\end{array}$ & 19 & 11 & $63.33 \%$ \\
\hline
\end{tabular}

It is observed that using Camshift-UKF, the performance accuracy is found to be $63.33 \%$.

\section{CAMSHIFT WITH BLBP FACE TRACKING METHOD}

The Camshift with Block Local Binary Pattern (BLBP) face tracking method improves the performance of the face tracking method improves the performance of the face tracking in the head gesture recognition [9]. The simulation results shows better performance of the face tracking using Camshift with BLBP, in head gesture recognition under the different environmental conditions such as cluttered background, shadow and sunshine.

Table IX shows the comparison of processing time of Camshift with BLBP algorithm and other algorithm for the face tracking in the head gesture recognition.

TABLE IX COMPARISON OF PROCESSING TIME OF FACE TRACKING USING CAMSHIFT WITH BLBP AND OTHER ALGORITHM

\begin{tabular}{|c|c|c|}
\hline Method & Min Face Size & Time Cost / Frame \\
\hline \multirow{2}{*}{$\begin{array}{l}\text { Basic Camshift } \\
\text { Algorithm }\end{array}$} & $100 * 100$ & $0.0406 \mathrm{~s}$ \\
\hline & $123 * 123$ & $0.0333 \mathrm{~s}$ \\
\hline \multirow{2}{*}{$\begin{array}{c}\text { Camshift with SIFT } \\
\text { Algorithm }\end{array}$} & $100 * 100$ & $0.0047 \mathrm{~s}$ \\
\hline & $123 * 123$ & $0.0043 \mathrm{~s}$ \\
\hline \multirow{2}{*}{$\begin{array}{c}\text { Camshift with KLT } \\
\text { Algorithm }\end{array}$} & $100 * 100$ & $0.0043 \mathrm{~s}$ \\
\hline & $123 * 123$ & $0.0030 \mathrm{~s}$ \\
\hline \multirow{2}{*}{$\begin{array}{c}\text { Camshift with UKF } \\
\text { Algorithm }\end{array}$} & $100 * 100$ & $0.0041 \mathrm{~s}$ \\
\hline & $123 * 123$ & $0.0026 \mathrm{~s}$ \\
\hline \multirow{2}{*}{$\begin{array}{c}\text { Camshift with BLBP } \\
\text { Algorithm }\end{array}$} & $100 * 100$ & $0.0015 \mathrm{~s}$ \\
\hline & $123 * 123$ & $0.0012 \mathrm{~s}$ \\
\hline
\end{tabular}

Table $\mathrm{X}$ shows the comparison of performance accuracy of Camshift with BLBP Algorithm and other algorithm for the face tracking in the head gesture recognition.

\section{TABLE X COMPARISON OF PERFORMANCE ACCURACY OF FACE TRACKING USING CAMSHIFT WITH BLBP AND OTHER} ALGORITHM

\begin{tabular}{|c|c|c|c|}
\hline Method & $\begin{array}{c}\text { Actual Faces } \\
\text { Tracked }\end{array}$ & $\begin{array}{c}\text { Faces Not } \\
\text { Tracked }\end{array}$ & Accuracy \\
\hline $\begin{array}{c}\text { Basic Camshift } \\
\text { Algorithm }\end{array}$ & 11 & 19 & $36.67 \%$ \\
\hline $\begin{array}{c}\text { Camshift with } \\
\text { SIFT Algorithm }\end{array}$ & 14 & 16 & $47.00 \%$ \\
\hline $\begin{array}{c}\text { Camshift with } \\
\text { KLT Algorithm }\end{array}$ & 17 & 13 & $57.00 \%$ \\
\hline $\begin{array}{c}\text { Camshift with } \\
\text { UKF Algorithm }\end{array}$ & 19 & 11 & $63.33 \%$ \\
\hline $\begin{array}{c}\text { Camshift with } \\
\text { BLBP Algorithm }\end{array}$ & 26 & 04 & $87.00 \%$ \\
\hline
\end{tabular}

It is observed that the performance accuracy of Face tracking using Camshift with BLBP, is $87.00 \%$ and found better than the other methods.

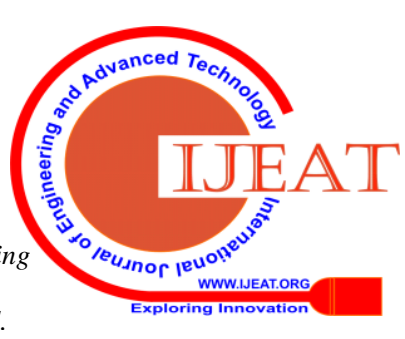




\section{Face Tracking Performance in Head Gesture Recognition System}

\section{CONCLUSION}

For the face tracking, the camshift is a very efficient face tracking method, for the indoor environmental conditions. However it is observed that the camshift algorithm cannot accurately track the face under outdoor environmental conditions such as cluttered background, shadow and sunshine.

So, we have done experimentation to use the integration of Adaboost Algorithm and Camshift with SIFT, Camshift with KLT, Camshift with UKF algorithms, and proposed method Camshift with BLBP Algorithm. We performed extensive experimentations and presented a comparative analysis of tracking performance of head gesture recognition system under cluttered backgrounds, shadow and sunshine conditions. It is shown that the performance accuracy of integration of Adaboost Algorithm and Camshift with BLBP Algorithm, is found better than the other methods. The percentage accuracy of the proposed method is found to be $87.00 \%$.

\section{REFERENCES}

1. Z. Yan, "A Target Tracking Algorithm based on Improved Camshift", Journal of Software Engineering and Applications, 2014, 7, 1065 1073

2. X. Huang, "Head Gesture Recognition based on Bayesian Network", Springer Verlag Berlin Heidelberg 2005.

3. S. Lichman, "A Smart Camera for Gesture Recognition and Gesture Controlled Web Navigation", $9^{\text {th }}$ International Conference on Control, Automation, Robotics and Vision, 5 - 8 December 2006, Grand Hyatt Singapore.

4. N. Kawarazaki, "Gesture Recognition System for Wheelchair Control using Sensor", 2013 IEEE International Conference.

5. P. Saikia, "Head Gesture Recognition using Optical Flow based Classification with Reinforcement of GMM based Background Subtraction System", 2013 IEEE International Conference.

6. D. Love, "Distinctive Image Features From Scale Invariant Keypoints", International Journal Computer Vision, 60 (2), 91 - 110, 2004.

7. T. Kanade, "Detection and Tracking of Point Features", Carnegie Mellon University Technical Report CMU-CS-91-132, April 1991.

8. W. Liang, "A Target Tracking Algorithm based on Improved Camshift and UKF", Journal of Software Engineering and Applications, 2014, 7, $1065-1073$

9. J. Peng, "An Improved Camshift based Particle Filter Algorithm for Face Tracking”, Springer Verlag Berlin Heidelberg, 2012.

10. M. Chouikha, "A New Algorithm for Tracking Objects in Videos of Cluttered Scenes", International Journal of Information Technology, Modeling and Computing, Volume 1, No. 2, Mat 2013.

11. F. Bremond, "Tracking Histogram of Oriented Gradients Descriptors for Gesture Recognition", $20096^{\text {th }}$ IEEE International Conference on Advanced Video and Signal based Surveillance.

12. A. Wang, "Improved Camshift with Adaptive Searching Window", International Journal of Soft Computing and Software Engineering, Volume 2, No. 3, 2012.

\section{AUTHORS PROFILE}

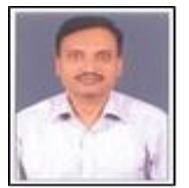

Rushikesh Bankar is a $\mathrm{Ph}$. D. Research Scholar, in the Department of Electronics Engineering at G H Raisoni College of Engineering, Nagpur (An Autonomous Institution), India. His Professional interests focus on Image Processing, Signal Processing, soft Computing and Intelligent Transportation System. E-Mail: rushi.shivbaba@gmail.com

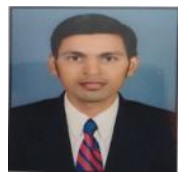

Dr. Suresh Salankar Professor and Head, G H Raisoni College of Engineering, Nagpur (An Autonomous Institution), India. His Research interests are in the Design and Evaluation of Learning Algorithms for Pattern Recognition Applications. This includes, in particular,
Neural Network Classifiers, Support Vector machines Classifier and Classifier Combing Strategies. He has published several papers in these areas. He is a member of the Institution of Engineers, India, Member of the Institution of Electronics and Telecommunication Engineers (IETE) and Member of Indian Society for Technical Education (ISTE).

E-Mail: suresh.salankar@raisoni.net 